\title{
Inoculant Fading-Resistance of Fe-Bearing Mg-3\% Al Alloys Refined by Carbon Combining with Calcium Addition
}

\author{
Chengbo Li, Cheng Wen, Jun Du*, Wenfang Li and Meiyan Zhan \\ School of Materials Science and Engineering, South China University of Technology, Guangzhou 510640, China
}

$\mathrm{Mg}-3 \% \mathrm{Al}$ alloys containing different trace Fe contents were treated by carbon combining with Ca inoculation. The holding time after being inoculation was adjusted from 5 to $80 \mathrm{~min}$. The effect of holding time on grain refinement and the structures of nucleating particles were systematically investigated. Significant grain refinement is obtained for the Mg-3\% Al alloys containing trace Fe refined by carbon combining with $\mathrm{Ca}$ inoculation. The grain size keep stable with prolonging the holding time and exhibit significant fading-resistance. The duplex-phase particles of Al-Fe coated with Al-C-rich phase could be easily observed and they should actually act as potent nuclei for Mg grains. The Ca content in the Al-C-rich shell is obviously higher than that in the $\mathrm{Mg}$ matrix. The segregation of $\mathrm{Ca}$ on the surfaces of different phases contributes to the formation of duplex-phase particles and keeps the duplex phase structure particles stable. Consequently, no inoculant-fading of carbon-inoculation occurred due to the high stability of the duplex phase structure particles. [doi:10.2320/matertrans.M2018208]

(Received June 26, 2018; Accepted October 1, 2018; Published November 25, 2018)

Keywords: grain refinement, carbon inoculation, fading-resistance

\section{Introduction}

Magnesium alloys are excellent light metal materials to be utilized in automotive, aerospace, computer, communication and consumer industries due to the low density and high specific strength. ${ }^{1)}$ However, magnesium alloys are also associated with some limitations, such as poor workability, poor corrosion resistance, low absolute strength and wear. Particularly, it is noticeable that $\mathrm{Mg}-\mathrm{Al}$ based alloys, which play a dominating role in commercial $\mathrm{Mg}$ alloys, have poor mechanical properties. These defects lead $\mathrm{Mg}-\mathrm{Al}$ based alloys to be incapable of meeting the requirements in many applications. ${ }^{2)}$ In general, grain refinement is a valid method to improve both mechanical properties and workability of Mg castings. ${ }^{3-5)}$ To date, some melt treatment processes of grain refinement for $\mathrm{Mg}-\mathrm{Al}$ based alloys have been intensively researched, including the superheating treatment, ${ }^{6-8)}$ the Elfinal process, ${ }^{9)}$ carbon inoculation ${ }^{10-12)}$ and solute addition. ${ }^{13)}$

Among these refining routes, carbon-inoculation and solute addition have been widely paid attention during the past two decades. ${ }^{14-18)}$ For these two refining routes, their refining mechanisms are different. The nucleation of $\mathrm{Al}-$ $\mathrm{C}$-rich particle which is formed in $\mathrm{Mg}-\mathrm{Al}$ melt is considered to be the mechanism of the carbon inoculation. ${ }^{16,17,19,20)}$ The grain refinement of solute addition is mainly controlled by constitutional supercooling. ${ }^{21)}$ Heterogeneous nucleation is based on the assumption that the nucleant particles should have good orientation relationships with the matrix in order to minimise the interfacial energy between the nuclei and the matrix. Until now, the exact Al-C particle which is formed in the carbon-inoculated $\mathrm{Mg}-\mathrm{Al}$ melt remain controversial. Researchers have proposed that $\mathrm{Al}_{4} \mathrm{C}_{3}, \mathrm{Al}_{2} \mathrm{OC}, \mathrm{Al}_{2} \mathrm{MgC}_{2}$ may be the heterogeneous nucleation particles. However, it is difficult to identify the exact phase composition since the Al-C-rich compounds are easily hydrolyzed. ${ }^{22,23)}$

As for the carbon-inoculated $\mathrm{Mg}-\mathrm{Al}$ alloy, recent researches demonstrate that grain refining potency of $\mathrm{Mg}$ -

*Corresponding author, E-mail: tandujun@sina.com
Al alloy was easily influenced by the two key factors: impurity elements and holding time..$^{9,11,24,25)}$ The impurity element of $\mathrm{Fe}$ is inevitable in the industrial $\mathrm{Mg}-\mathrm{Al}$ alloys. ${ }^{26)}$ The content of impurity iron in the primary magnesium is usually higher than $100 \mathrm{ppm}$, which is thought to be one of the main causes of poor corrosion resistance and low plasticity in commercial magnesium alloys. As for the $\mathrm{Mg}-\mathrm{Al}$ alloys refined by carbon-inoculated, Fe was known as an unfavourable element for grain refinement by transforming $\mathrm{Al}_{4} \mathrm{C}_{3}$ into $\mathrm{Al}-\mathrm{C}-\mathrm{Fe}$-rich particles or coating on the surface of $\mathrm{Al}_{4} \mathrm{C}_{3}$ particles. ${ }^{27)}$ Contrary to the observations reported previously, Pan et al. ${ }^{28)}$ indicated that the $\mathrm{Al}-\mathrm{C}-\mathrm{O}-\mathrm{Fe}-\mathrm{Mn}-$ rich particles could constitute the heterogeneous nucleation particles of primary $\mathrm{Mg}$ grains. Fe was a favourable element in the constitution of the nucleating particles rather than inhibiting element. The following research carried out by $\mathrm{Du}$ et al. reported that whether $\mathrm{Fe}$ inhibits the grain refinement of the $\mathrm{Mg}-\mathrm{Al}$ alloy or not depends on the sequence of $\mathrm{Fe}$ addition and carbon inoculation. ${ }^{25)}$ The result shows that Fe has no distinct effect on the grain refinement of $\mathrm{Mg}-\mathrm{Al}$ alloy by carbon inoculation in the condition of $\mathrm{Fe}$ addition before carbon inoculation. In contrast, Fe played an unfavourable role in the grain refinement under the condition that the $\mathrm{Mg}-\mathrm{Al}$ melt was fully inoculated by carbon before $\mathrm{Fe}$ addition. Based on this research, the present authors continued to investigate the influence of $0.1 \% \mathrm{Fe}$ addition on grain refinement of $\mathrm{Mg}-3 \% \mathrm{Al}$ alloy refined by carbon and $\mathrm{Ca}$ inoculations. ${ }^{27)}$ Interestingly, the result shows that the existence of $\mathrm{Ca}$ could effectively avoid grain coarsening by $\mathrm{Fe}$, regardless of the $\mathrm{Fe}$ addition sequence in the carboninoculated $\mathrm{Mg}-\mathrm{Al}$ melt. A new concept of poisoning-free effect was provided in this study. Likewise, the same poisoning-free effect was substantiated in the grain refinement of $\mathrm{Mg}-3 \% \mathrm{Al}$ alloy contained $0.1 \% \mathrm{Fe}$ refined by carbon and $\mathrm{Sr}$ addition. ${ }^{13)}$

Moreover, holding time after carbon inoculation was also an important factor for grain refining efficiency. It is well known that an important phenomenon of fading effect is an inevitable issue during inoculation. The grain refining efficiency decreases with prolonging the holding time. This 
decreasing effectiveness is known as inoculant fading, which is closely related to the stability of nuclei and remaining number of effective inoculant particles. ${ }^{29-35)}$ In the previous researches performed by Chen et al., the grain sizes increased significantly with the extension of holding time for the AZ91 alloy inoculated by $\mathrm{MgCO}_{3}$ and $\mathrm{SiC}$, i.e., obvious inoculant fading phenomenon was observed. ${ }^{36,37)}$ They believed that the number of effective nucleant substrates was decreased when the holding time was extended. However, no evidence was provided in their studies. In our recent study, no obvious inoculant fading was found when the holding time was prolonged to $120 \mathrm{~min}$ in high purity $\mathrm{Mg}-3 \% \mathrm{Al}$ alloy. ${ }^{11)}$ However, the existence of $0.1 \% \mathrm{Fe}$ could accelerate the inoculant-fading and the grain refining efficiency disappeared when the holding time was over than $30 \min ^{38)}$

It is well known that the impurity element $\mathrm{Fe}$ is inevitable during the preparation of magnesium alloys.9,13,26) Carbon combining with $\mathrm{Ca}$ inoculation is an effective way to refine $\mathrm{Mg}-\mathrm{Al}$ alloys and the poisoning influence of $\mathrm{Fe}$ on grain refinement can be inhibited due to the existence of $\mathrm{Ca} .{ }^{27}$ ) However, few studies were conducted to investigate the inoculant fading-resistance of $\mathrm{Mg}-3 \% \mathrm{Al}$ alloy contained trace $\mathrm{Fe}$ refined by carbon combining with $\mathrm{Ca}$ inoculation. In the present study, the $\mathrm{Mg}-3 \% \mathrm{Al}$ melt containing different trace $\mathrm{Fe}$ were treated by carbon combining with $\mathrm{Ca}$ inoculation. The holding time after carbon inoculation was extended from $5 \mathrm{~min}$ to $80 \mathrm{~min}$. The following key issues are clarified: (1) how grain size changes with the holding time; (2) whether Fe accelerates inoculant-fading of carbon combining with $\mathrm{Ca}$ inoculation; (3) how the inoculating particles changes in the carbon-inoculated $\mathrm{Mg}-3 \% \mathrm{Al}$ alloy containing trace $\mathrm{Fe}$ as a result of the $\mathrm{Ca}$ existence. Identification of these issues will contribute to deeply disclose the influence mechanism of $\mathrm{Ca}$ on grain refinement of carbon-inoculated $\mathrm{Mg}-\mathrm{Al}$ alloys containing trace $\mathrm{Fe}$.

\section{Experimental Procedure}

$\mathrm{Mg}-3 \% \mathrm{Al}$ alloy was made from high-purity $\mathrm{Mg}(99.98 \%)$ and $\mathrm{Al}(99.99 \%)$. Mg-10\% Ca master alloy were utilized in the present research. The graphite, magnesium and aluminum powders with mass ratio of 1:4:5 were mixed and prepared into cylindrical pellets $(\Phi 10 \times 5 \mathrm{~mm})$. The pellets were prepared by cold isostatic press (CIP) under a pressure of $150 \mathrm{MPa}$ for 2 minutes. The addition contents of carbon and calcium were both $0.2 \%$ (mass ratio, the same below) of the melt. Al-15\%Fe master alloys was used for Fe source. The different addition contents of $\mathrm{Fe}$ were $0.02 \%, 0.05 \%$ and $0.1 \%$. About $350 \mathrm{~g} \mathrm{Mg}-3 \% \mathrm{Al}$ alloy was melted at $780^{\circ} \mathrm{C}$ in the high-purity $\mathrm{MgO}$ crucible under the protection of flux $\left(\mathrm{SF}_{6}\right.$ and $\left.\mathrm{N}_{2}\right)$ using an electrical resistance furnace. After that, $\mathrm{Mg}-10 \% \mathrm{Ca}$ master alloy was plunged into the $\mathrm{Mg}-3 \% \mathrm{Al}$ melt. Then the carbon-containing pellets were added into the melt. During the inoculation, the melt was stirred manually with an $\mathrm{MgO}$ rod for a few seconds before being poured into a mould. After being held for different time $(5,20,30,50$ and $80 \mathrm{~min}$ ), the melt was poured into a tapered iron mould preheated at $500^{\circ} \mathrm{C}$. The diameter of the tapered iron mould was $\Phi 20 \times \Phi 22 \times 30 \mathrm{~mm}$. It should be note that the melt was stirred before being poured for different holding time. All the samples with the different holding time were poured from the same melt. It is well known that the cooling rate has an effect on the grain size. ${ }^{39,40)}$ In this study the cooling rate of all samples were the same, therefore the effect of cooling rate on grain size will not be considered. Metallographic specimens were taken from the position of $15 \mathrm{~mm}$ from the samples bottom. Each sample was divided into two parts, one part was treated by heat treatment to observe the grain microstructures. The other part was without heat treatment to observe the nucleated particles. The heat-treated specimens $\left(420^{\circ} \mathrm{C}\right.$ for six hours and then cooled in the air) were polished and subsequently chemically etched. The etchant consists of picric acid $(4.2 \mathrm{~g})$, glacial acetic acid $(10 \mathrm{ml})$, ethyl alcohol $(70 \mathrm{ml})$ and distilled water $(10 \mathrm{ml})$. Leica DFC320 optical microscope were utilized to observe the grain microstructures. The grain size was measured by linear intercept method (ASTM Standard E112-88 ${ }^{41)}$ ). To disclose the nucleation particles and their compositions, the cast samples etched by 2 vol $\%$ nitride acid ethanol solution were subsequently observed by electron probe microanalyzer (EPMA-1600) equipped with EDAX Genesis.

\section{Results}

\subsection{Grain refining efficiency}

The grain morphologies of the $\mathrm{Mg}-3 \% \mathrm{Al}$ alloy containing different trace $\mathrm{Fe}$ are displayed in Fig. 1. The grain size of original $\mathrm{Mg}-3 \% \mathrm{Al}$ alloy is about $434 \pm 23 \mu \mathrm{m}$, as shown in Fig. 1(a). The grain size of $\mathrm{Mg}-3 \% \mathrm{Al}$ alloy is increased to $557 \pm 46 \mu \mathrm{m}$, after $0.02 \% \mathrm{Fe}$ addition. Whereas, the grain size is decreased to $425 \pm 26 \mu \mathrm{m}$ and $419 \pm 12 \mu \mathrm{m}$ when $0.05 \%$ and $0.1 \% \mathrm{Fe}$ were further added, respectively. No obvious grain refinement phenomenon appeared after $\mathrm{Fe}$ addition. The results indicate that Fe could not refine $\mathrm{Mg}-$ $3 \% \mathrm{Al}$ alloy and the grain size remain coarse.

Figure 2 shows the grain morphologies of the $\mathrm{Mg}-3 \% \mathrm{Al}$ alloy refined by carbon combining with $\mathrm{Ca}$ inoculation with different holding time. The contents of $\mathrm{C}$ and $\mathrm{Ca}$ addition were $0.2 \%$. The grain morphology of the sample with the
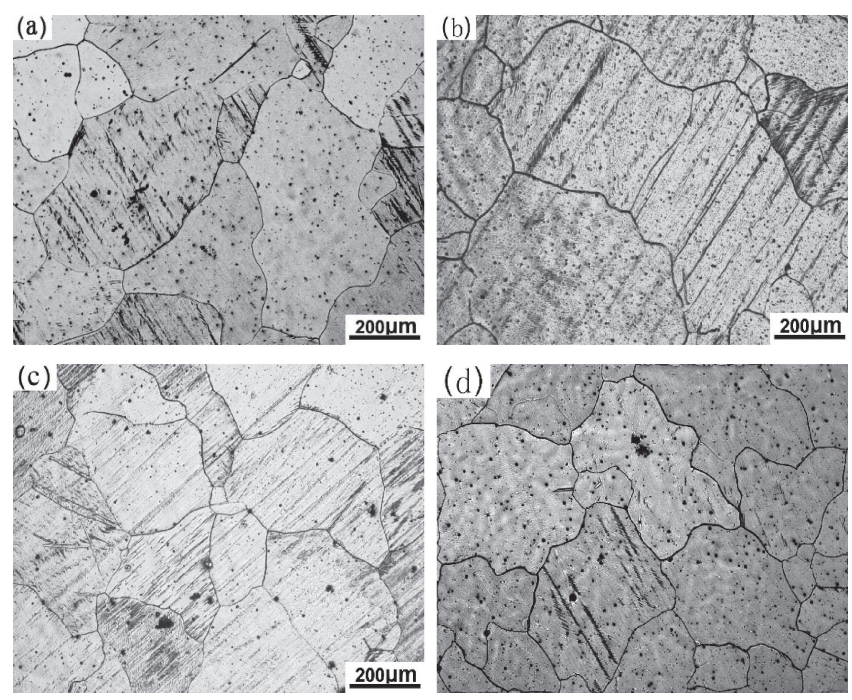

Fig. 1 Grain morphologies of the $\mathrm{Mg}-3 \% \mathrm{Al}$ alloy with different $\mathrm{Fe}$ addition contents ((a) $0 \% \mathrm{Fe}$; (b) $0.02 \% \mathrm{Fe}$; (c) $0.05 \% \mathrm{Fe}$; (d) $0.1 \% \mathrm{Fe}$ ). 

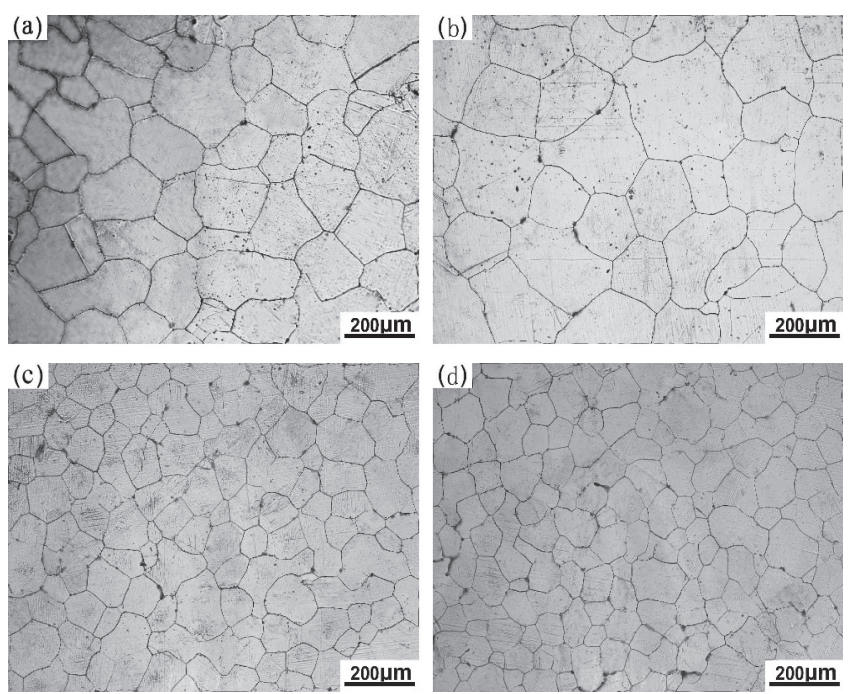

Fig. 2 Grain morphologies of the $\mathrm{Mg}-3 \% \mathrm{Al}$ alloy refined by $0.2 \% \mathrm{C}$ combining with $0.2 \% \mathrm{Ca}$ inoculation with different holding time: (a) 5 min; (b) $20 \mathrm{~min}$; (c) $30 \mathrm{~min}$; (d) $80 \mathrm{~min}$.

holding time of $50 \mathrm{~min}$ was not listed to avoid repeating. Obviously, the grain size of the $\mathrm{Mg}-3 \% \mathrm{Al}$ alloy was significant refined by carbon combining with $\mathrm{Ca}$ inoculation. When the holding time was $5 \mathrm{~min}$, the grain size was sharply reduced from $434 \pm 23 \mu \mathrm{m}$ (shown in Fig. 1(a)) to about $188 \pm 5 \mu \mathrm{m}$ (Fig. 2(a)). With prolonging the holding time, the grain size remained stable and no fading phenomenon occurred, as shown in Figs. 2(b) to (d). Moreover, the finest grain size with about $118 \mu \mathrm{m}$ was achieved when the holding time was prolonged to $80 \mathrm{~min}$. The result shows that the $\mathrm{Mg}-3 \% \mathrm{Al}$ alloy refined by carbon combining with $\mathrm{Ca}$ inoculation had obvious advantage of fading-resistance.

The effects of $\mathrm{Fe}$ addition content and holding time on grain refinement of $\mathrm{Mg}-3 \% \mathrm{Al}$ alloy refined by carbon combining with $\mathrm{Ca}$ inoculation were mainly investigated in this research. The grain morphologies of the parts of samples are shown in Fig. 3. Figures 3(a-d) present the grain morphologies of the $\mathrm{Mg}-3 \% \mathrm{Al}$ alloy containing $0.02 \% \mathrm{Fe}$ refined by carbon combining with $\mathrm{Ca}$ inoculation with the holding time of $5 \mathrm{~min}, 20 \mathrm{~min}, 30 \mathrm{~min}$ and $80 \mathrm{~min}$. The grain size is sharply decreased from $531 \mu \mathrm{m}$ (shown in Fig. 1(b)) to $232 \mu \mathrm{m}$ and $215 \mu \mathrm{m}$ when the holding time was extended to $20 \mathrm{~min}$ and $30 \mathrm{~min}$, respectively. The grain size was further refined to $133 \mu \mathrm{m}$ with prolonging the holding time to $80 \mathrm{~min}$. Figures $3(\mathrm{e}-\mathrm{f})$ and Figs. $3(\mathrm{~g}-\mathrm{h})$ show the microstructures of the $\mathrm{Mg}-3 \% \mathrm{Al}$ alloy containing $0.05 \% \mathrm{Fe}$ and $0.1 \% \mathrm{Fe}$ refined by carbon combining with $\mathrm{Ca}$ inoculation with the holding time of $30 \mathrm{~min}$ and $80 \mathrm{~min}$, respectively. Likewise, the grain sizes were very small and remarkable grain refining efficiency could be found even though the contents of $\mathrm{Fe}$ was increased to $0.05 \%$ and $0.1 \%$. Also, no inoculant fading occurred with holding time extending to $80 \mathrm{~min}$.

Figure 4 illustrates the influence of holding time on grain sizes of the $\mathrm{Mg}-3 \% \mathrm{Al}$ alloy with different contents of $\mathrm{Fe}$ refined by carbon combining with $\mathrm{Ca}$ inoculation. The grain sizes of the $\mathrm{Mg}-3 \% \mathrm{Al}$ alloy containing different trace $\mathrm{Fe}$ contents are coarse (shown in Fig. 1). After being inoculated by carbon combining with $\mathrm{Ca}$, their grain sizes were
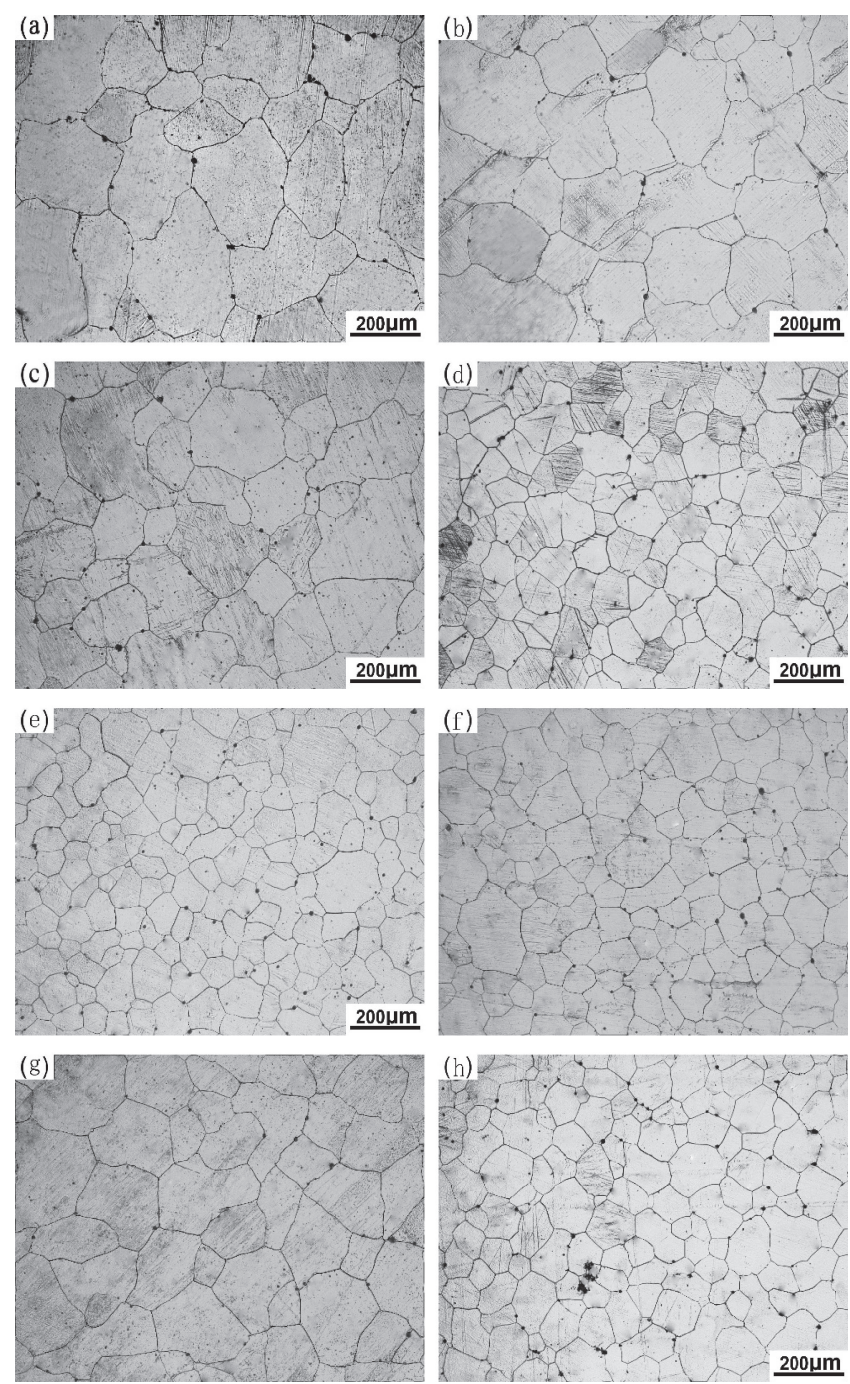

Fig. 3 Grain morphologies of the $\mathrm{Mg}-3 \% \mathrm{Al}$ alloy containing different $\mathrm{Fe}$ addition contents refined by carbon combining with $\mathrm{Ca}$ inoculation with the different holding time. (a)-(d) $\mathrm{Mg}-3 \% \mathrm{Al}-0.02 \% \mathrm{Fe}$ with the holding time of $5 \mathrm{~min}, 20 \mathrm{~min}, 30 \mathrm{~min}$ and $80 \mathrm{~min}$; (e)-(f) $\mathrm{Mg}-3 \% \mathrm{Al}-0.05 \% \mathrm{Fe}$ with the holding time of $30 \mathrm{~min}$ and $80 \mathrm{~min}$; (g)-(h) $\mathrm{Mg}-3 \% \mathrm{Al}-0.1 \% \mathrm{Fe}$ with the holding time of $30 \mathrm{~min}$ and $80 \mathrm{~min}$.

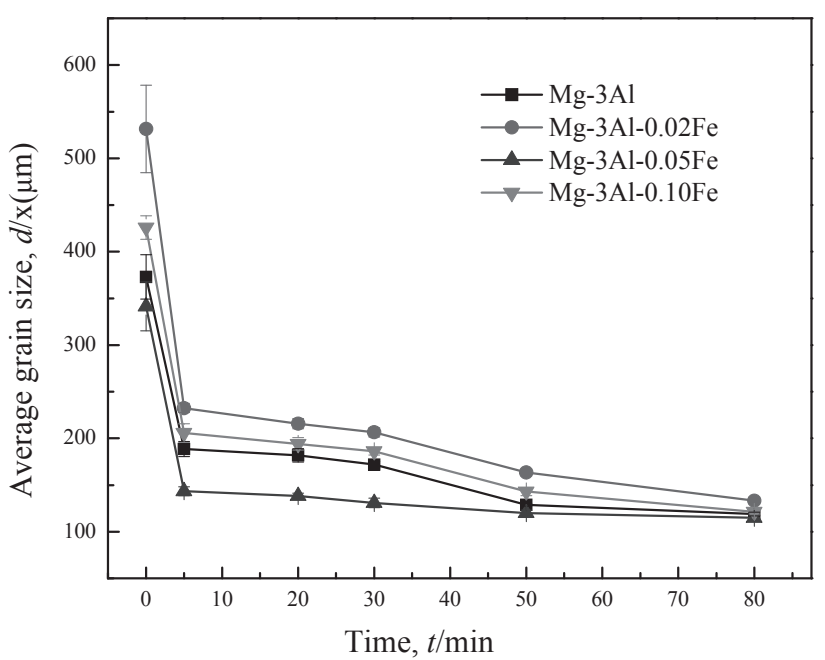

Fig. 4 Effect of holding time on grain sizes of the $\mathrm{Mg}-3 \% \mathrm{Al}$ alloy with different $\mathrm{Fe}$ contents refined by carbon combining with $\mathrm{Ca}$ inoculation. 

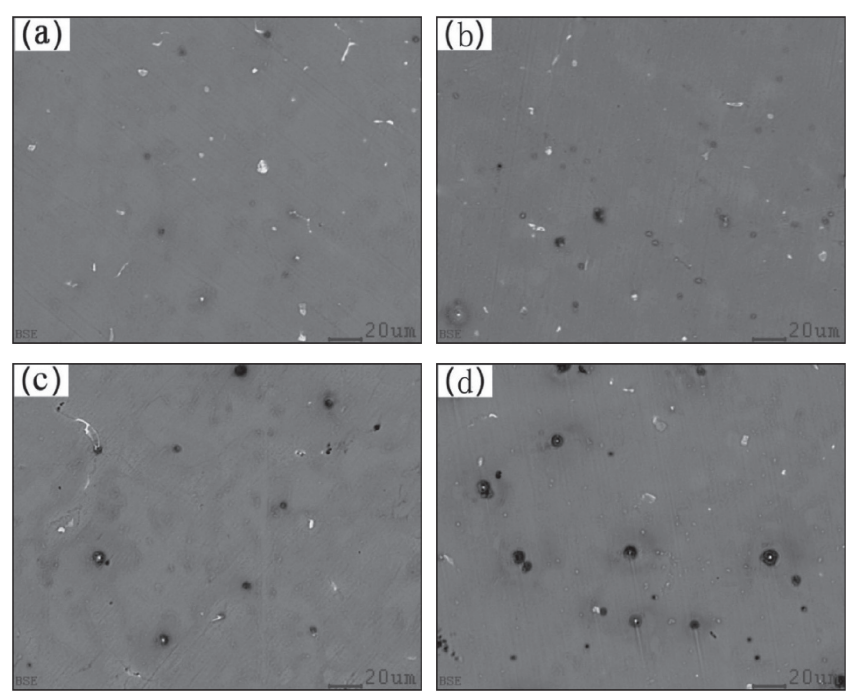

Fig. 5 Low magnification EPMA-BSE micrographs of the $\mathrm{Mg}-3 \% \mathrm{Al}$ alloy containing different trace Fe contents refined by carbon combining with $\mathrm{Ca}$ inoculation with the holding time of $5 \mathrm{~min}($ (a) $0 \% \mathrm{Fe}$; (b) $0.02 \% \mathrm{Fe}$; (c) $0.05 \% \mathrm{Fe}$; (d) $0.1 \% \mathrm{Fe}$ ).

significantly refined even though the holding time is $5 \mathrm{~min}$. With increasing in the holding time, the grain sizes gradually decrease and keep stable when the holding time was over than $50 \mathrm{~min}$. As for the effect of Fe content is concerned, the finest grain size can be fined in the sample containing with $0.05 \% \mathrm{Fe}$. The grain size is coarse when the Fe content is $0.02 \%$. Finally, the grain sizes of all samples are almost same when the holding time is over than $50 \mathrm{~min}$. The smallest grain sizes of all samples are obtained at $80 \mathrm{~min}$ and their grain sizes are about $115 \mu \mathrm{m}$. Obviously, the grain refining efficiency of carbon combining with $\mathrm{Ca}$ inoculation did not diminish even though the holding time was extended to $80 \mathrm{~min}$. In our previous study, it was found that $0.1 \% \mathrm{Fe}$ can accelerate the inoculant-fading for the $\mathrm{Mg}-3 \% \mathrm{Al}$ melt refined only by carbon inoculation. When the holding time exceeded $30 \mathrm{~min}$, the grain refinement phenomenon was disappeared. ${ }^{38)}$ Based on the above results, it can be concluded that $\mathrm{Fe}$ had no effect on $\mathrm{Mg}-3 \% \mathrm{Al}$ alloy refined by carbon combining with $\mathrm{Ca}$ inoculation. Moreover, the existence of $\mathrm{Ca}$ in the melt could inhibit the inoculant-fading for the $\mathrm{Mg}-3 \% \mathrm{Al}$ melt containing trace $\mathrm{Fe}$ inoculated by carbon.

\subsection{Investigation of nucleating particles}

Detailed microscopic observation was conducted for the refined samples by EPMA in the backscattered electron model (BSE). Figure 5 shows the typical low magnification EPMA micrographs of the as-cast $\mathrm{Mg}-3 \% \mathrm{Al}$ alloys containing different trace Fe refined by carbon combining with $\mathrm{Ca}$ inoculation with the holding time of $5 \mathrm{~min}$. There exist many particles of white particles and tiny gray particles in the sample without Fe addition, as shown in Fig. 5(a). In the samples containing Fe (Figs. 5(b) to (c)), there exist three types of particles, i.e., white particles, tiny gray particles and particular particles with white core surrounded by grey halos. The white and gray particles are decreased sharply with the content of $\mathrm{Fe}$ increased. Figure 6 presents the micrographs of three different $\mathrm{Fe}$-bearing $\mathrm{Mg}-3 \% \mathrm{Al}$ alloys refined by
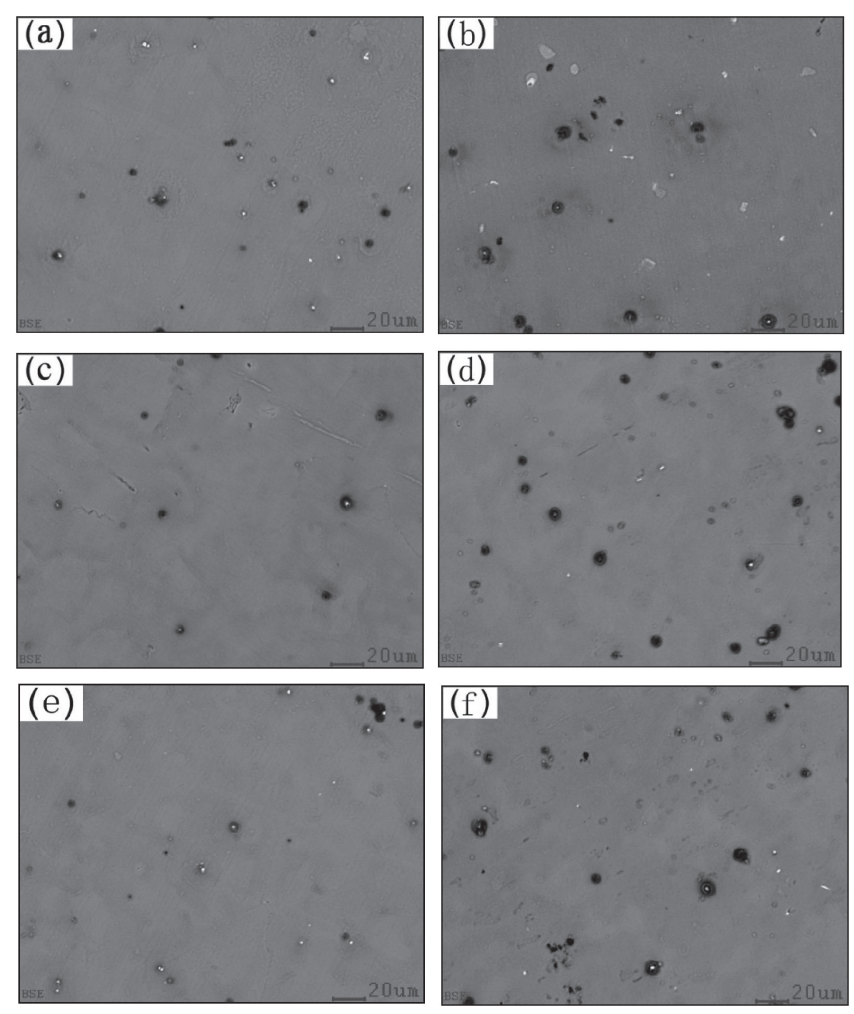

Fig. 6 Low magnification EPMA micrographs of $\mathrm{Mg}-3 \% \mathrm{Al}$ alloy containing trace different $\mathrm{Fe}$ addition refined by carbon combining with $\mathrm{Ca}$ inoculation. (a)-(b) $\mathrm{Mg}-3 \% \mathrm{Al}-0.02 \% \mathrm{Fe}$ with the holding time of $30 \mathrm{~min}$ and $80 \mathrm{~min}$; (c)-(d) $\mathrm{Mg}-3 \% \mathrm{Al}-0.05 \% \mathrm{Fe}$ with the holding time of $30 \mathrm{~min}$ and $80 \mathrm{~min}$; (e)-(f) $\mathrm{Mg}-3 \% \mathrm{Al}-0.1 \% \mathrm{Fe}$ with the holding time of $30 \mathrm{~min}$ and $80 \mathrm{~min}$.

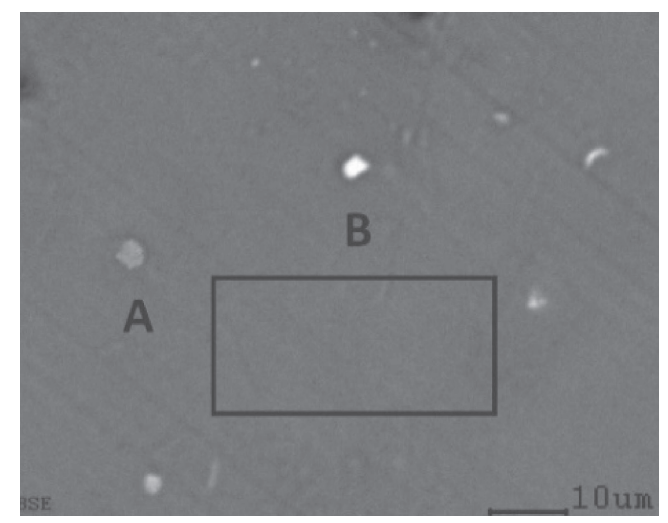

Fig. 7 EPMA analysis of $\mathrm{Mg}-3 \% \mathrm{Al}$ refined by carbon combining with $\mathrm{Ca}$ inoculation for $5 \mathrm{~min}$.

carbon combining with $\mathrm{Ca}$ inoculation with the holding time of 30 and $80 \mathrm{~min}$. There exist many particular particles in both refined alloys even the holding time is prolonged to $80 \mathrm{~min}$. The morphology of these particular particles did not change and their number evidently increased.

To disclose the accurate chemical compositions, two typical particles existed in the sample of $\mathrm{Fe}$-free $\mathrm{Mg}-3 \% \mathrm{Al}$ alloy refined by carbon combine $\mathrm{Ca}$ inoculation were characterized by EPMA-EDS under high magnification, as shown in Fig. 7. The chemical analysis of particle A, B and the $\mathrm{Mg}$ matrix were shown in Table 1. The carbon and oxygen elements in the Mg matrix should be the resultant of 
Table 1 Chemical compositions of the particle A, B, and Matrix as shown in Fig. 7

\begin{tabular}{|c|c|c|c|c|c|c|}
\hline \multirow{2}{*}{ Element } & \multicolumn{2}{|c|}{ Particle A } & \multicolumn{2}{|c|}{ Particle B } & \multicolumn{2}{|c|}{ Matrix } \\
\hline & $W t \%$ & $A t \%$ & $W t \%$ & $A t \%$ & $W t \%$ & $A t \%$ \\
\hline C & 8.27 & 14.71 & 4.50 & 10.01 & 5.36 & 10.20 \\
\hline$o$ & 5.77 & 8.03 & 1.70 & 2.83 & 2.81 & 4.02 \\
\hline$M g$ & 69.26 & 63.47 & 23.17 & 25.47 & 88.91 & 83.38 \\
\hline$A l$ & 16.70 & 13.79 & 45.24 & 44.82 & 2.70 & 2.29 \\
\hline $\mathrm{Ca}$ & 0 & 0 & 25.39 & 16.87 & 0.22 & 0.12 \\
\hline
\end{tabular}

contamination during sample polishing and etching. It can be found that the particle $\mathrm{A}$ consists of $\mathrm{Al}, \mathrm{C}$ and $\mathrm{O}$ elements since their contents are obviously larger than those in the $\mathrm{Mg}$ matrix. As for the particle $\mathrm{B}$, its contents of $\mathrm{C}$ and $\mathrm{O}$ are low and almost same with the $\mathrm{Mg}$ matrix. However, the contents of $\mathrm{Al}$ and $\mathrm{Ca}$ elements are remarkably higher than those of the particle $\mathrm{A}$ and $\mathrm{Mg}$ matrix. Its $\mathrm{Al}$ and $\mathrm{Ca}$ contents are $45.24 \%$ and $25.39 \%$, which were far exceeded the addition contents of $0.2 \% \mathrm{Ca}$ and $3 \% \mathrm{Al}$. Therefore, the particles $\mathrm{A}$ and $\mathrm{B}$ should be $\mathrm{Al}-\mathrm{C}-\mathrm{O}-$-rich and $\mathrm{Al}-\mathrm{Ca}-$ rich compounds, respectively.

Many particular particles and tiny white particles were easily detected in the $\mathrm{Mg}-3 \% \mathrm{Al}$ alloys containing $0.02 \% \mathrm{Fe}$, as shown in Fig. 8(a). The two particles existed in the central area were analysed under high magnification to disclose the precise characteristics, as shown in Fig. 8(b). Obvious single phase structure could be observed for the particle A. However, the particle B assumed a typical duplex phase structure with a white core coated with a black shell. The compositions of A and B were characterized by EPMA line scanning and point analyses. The line scanning result is displayed in Fig. 8(c). Through EPMA line analysis, it can be seen that the elements of $\mathrm{Al}, \mathrm{O}$ and $\mathrm{Ca}$ have high peaks at the position of particle A. The composition details obtained
Table 2 Chemical compositions of the particle A as shown in Fig. 8(b).

\begin{tabular}{ccc}
\hline Element & $\boldsymbol{W t} \%$ & $\boldsymbol{A t} \%$ \\
\hline $\boldsymbol{C}$ & 4.99 & 9.74 \\
$\boldsymbol{O}$ & 4.41 & 6.47 \\
$\boldsymbol{M g}$ & 69.70 & 67.26 \\
$\boldsymbol{A l}$ & 15.40 & 13.39 \\
$\boldsymbol{C a}$ & 4.97 & 2.91 \\
\hline
\end{tabular}

by point analysis are given in Table 2 . The contents of $\mathrm{Al}, \mathrm{Ca}$ and $\mathrm{C}$ were $15.40 \%, 4.97 \%$ and $4.99 \%$, respectively. It can be seen that the contents of $\mathrm{Al}$ and $\mathrm{Ca}$ were higher than $\mathrm{Mg}$ matrix and content of $\mathrm{C}$ was almost the same with $\mathrm{Mg}$ matrix. Consequently, particle A should be Al-Ca-rich compound. Unlike the particle A, there exist two obvious peaks of $\mathrm{O}$ element in the position of bright core edge, as shown in the center of particle B. However, Al and Fe elements had only one peak in the center of bright core. It can be reasonably inferred that there existed a shell coated on the surface of $\mathrm{Al}-\mathrm{Fe}$ compound. The compositions of the shell and core areas are listed in Table 3. In the particle B, the compositions of $\mathrm{Al}$ and $\mathrm{Fe}$ in the center core are higher than those in the shell while the content of $\mathrm{C}, \mathrm{O}$ are lower. Obviously, Particle $\mathrm{B}$ is a duplex phase structure that $\mathrm{Al}-\mathrm{C}-\mathrm{O}$-rich phase coated on the Al-Fe-rich phase.

Figure 9 shows EPMA-EDS line analysis results of a typical duplex-phase particle in the sample with $0.05 \% \mathrm{Fe}$. The chemical compositions of the core and shell are given in the Table 4. Obviously, the contents of $\mathrm{Al}$ and $\mathrm{Fe}$ in the core are higher than those in the shell of the particle. In the edge of the core, there also existed two obvious peaks of $\mathrm{O}$ and $\mathrm{C}$ element. It is found out that the content of $\mathrm{Ca}$ both in core and shell is higher than that in $\mathrm{Mg}$ matrix. Known from the Fig. 6, the particles with duplex-phase structure remain stable in the sample with prolonging the holding time to $80 \mathrm{~min}$.
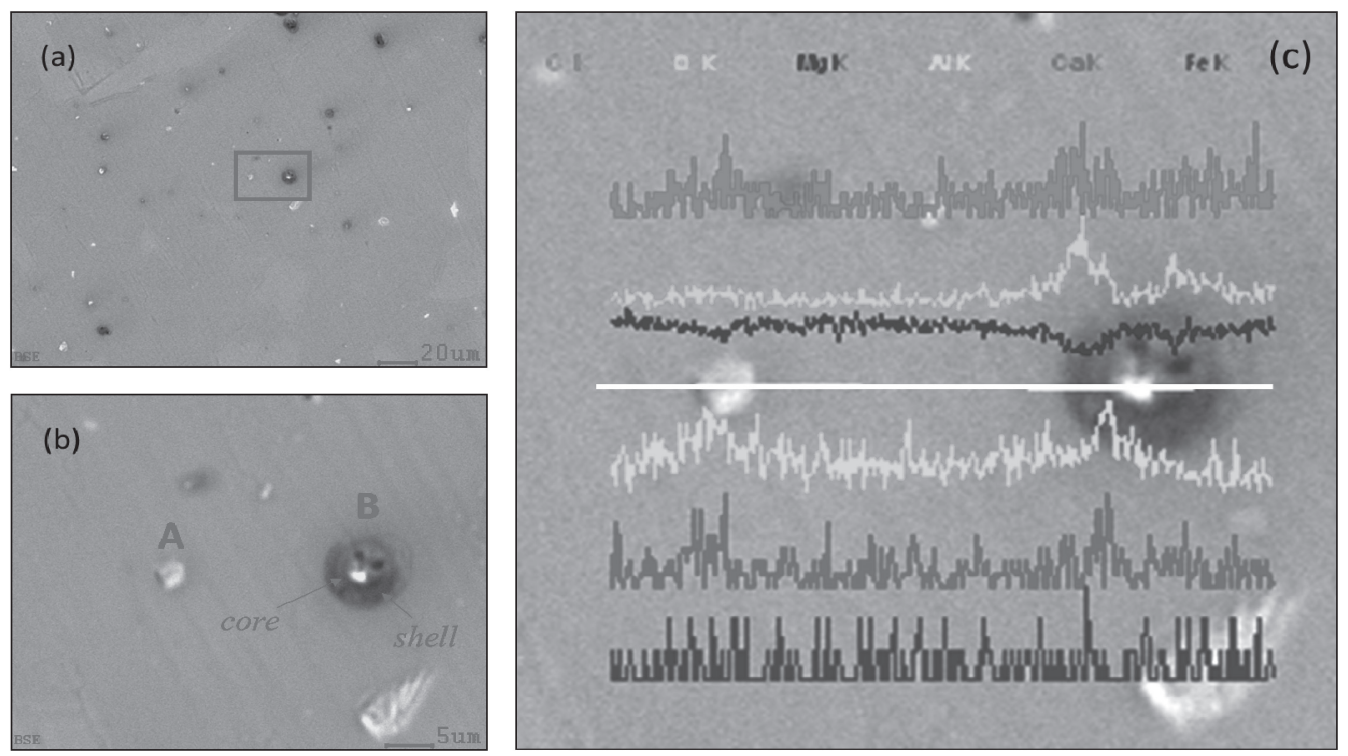

Fig. 8 EPMA analysis of $\mathrm{Mg}-3 \% \mathrm{Al}-0.02 \%$ Fe refined by carbon combining with $\mathrm{Ca}$ inoculation with the holding time of 5 min. (a)-(d) Low and high magnification EPMA micrographs; Table 2 and 3: EPMA line and point analyses of the particles. 
Table 3 Chemical compositions of the particle B (core and shell) as shown in Fig. 8(b).

\begin{tabular}{ccccc}
\hline \multirow{2}{*}{ Element } & \multicolumn{2}{c}{ Core } & \multicolumn{2}{c}{ Shell } \\
& $\boldsymbol{W} \boldsymbol{t} \%$ & $\boldsymbol{A t} \%$ & $\boldsymbol{W t} \%$ & $\boldsymbol{A t} \boldsymbol{1}$ \\
\hline $\boldsymbol{C}$ & 5.31 & 10.25 & 8.09 & 14.61 \\
$\boldsymbol{O}$ & 6.07 & 8.80 & 11.38 & 15.43 \\
$\boldsymbol{M g}$ & 72.97 & 69.61 & 70.71 & 63.10 \\
$\boldsymbol{A l}$ & 10.45 & 8.99 & 7.01 & 5.63 \\
$\boldsymbol{C a}$ & 1.15 & 0.67 & 0.89 & 0.48 \\
$\boldsymbol{F e}$ & 4.05 & 1.68 & 0.18 & 0.07 \\
\hline
\end{tabular}

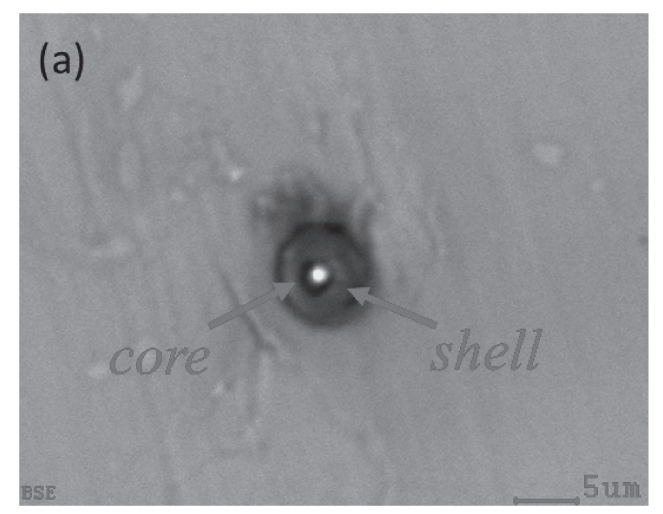

Fig. 9 EPMA analysis of $\mathrm{Mg}-3 \% \mathrm{Al}-0.05 \% \mathrm{Fe}$ refined by carbon combining with Ca inoculation with the holding time of 5 min. a: High magnification EPMA micrographs and the chemical compositions of the core and shell; Table 4: EPMA line analysis of the duplex-phase particle.

To clearly disclose the element distributions for the duplex-phase particles, the EPMA-WDS map analysis results are illustrated in Fig. 10 for the sample containing $0.05 \% \mathrm{Fe}$ with the holding time of $80 \mathrm{~min}$. Three typical duplex phase structure particles were chosen for observation in the Fig. 10(a). The concentration of Fe was found to be high (red and blue points) in the center of three typical duplex phase structure particles, as shown in Fig. 10(b). In Figs. 10(c) and (d), it is notable that the $\mathrm{C}$ and $\mathrm{O}$ element concentrations are also high in the three duplex structure position and constitute a complete circle. In the center of the circle, there were little $\mathrm{C}$ and $\mathrm{O}$ element. Moreover, the distributions of $\mathrm{C}$ and $\mathrm{O}$ element always overlap. This observation provides obvious evidence that $\mathrm{Al}-\mathrm{Fe}$-rich phase was coated by $\mathrm{Al}-\mathrm{C}-\mathrm{O}$-rich phase and it is corresponded with the result of the line and point analysis. Obviously, Ca element was distributed around the duplex structure position, as shown in Fig. 10(e). Different from the $\mathrm{C}$ and $\mathrm{O}$ element, the distribution of $\mathrm{Ca}$ element did not form a complete circle. This phenomenon indicates that $\mathrm{Ca}$ element was segregated towards to duplex phase particles during the solidification. It should be noted that there exist many little tiny particles of $\mathrm{Ca}$ and distributed in the $\mathrm{Mg}$ grain randomly. It should be noted that in the position of Fe element, the concentration of $\mathrm{Al}$ was found to be high, as shown in Fig. 10(f). These particles were actually Al-Carich particles which were formed by $\mathrm{Al}$ and $\mathrm{Ca}$ reaction during solidification process.

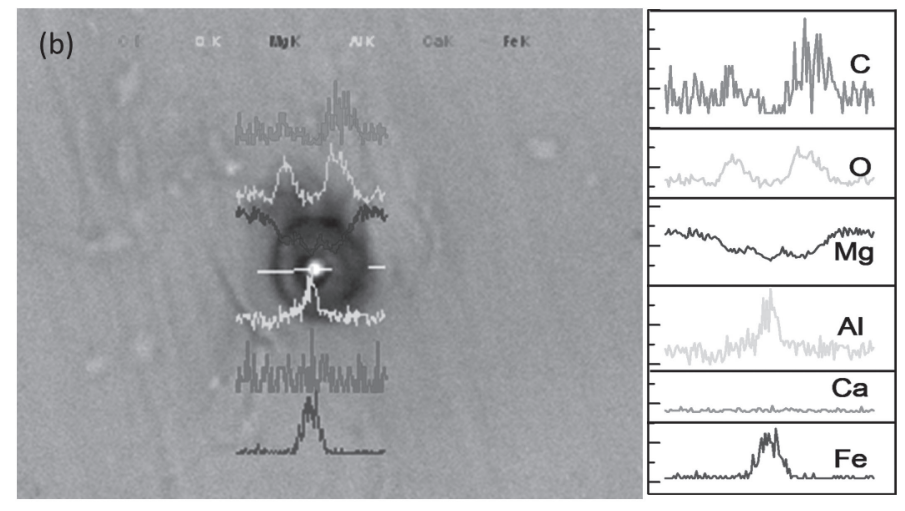

Table 4 Chemical compositions of the core and shell as shown in Fig. 9.

\begin{tabular}{rllll}
\hline \multirow{2}{*}{ Element } & \multicolumn{2}{c}{ Core } & \multicolumn{2}{c}{ Shell } \\
& $\boldsymbol{W t} \boldsymbol{t} \boldsymbol{A t} \%$ & $\boldsymbol{W t} \%$ & $\boldsymbol{A t} \boldsymbol{0}$ \\
\hline $\boldsymbol{C}$ & 2.52 & 6.50 & 17.41 & 27.23 \\
$\boldsymbol{O}$ & 4.81 & 9.30 & 25.33 & 29.74 \\
$\boldsymbol{M g}$ & 33.56 & 42.69 & 50.48 & 39.01 \\
$\boldsymbol{A l}$ & 14.61 & 16.75 & 4.14 & 2.88 \\
$\boldsymbol{C a}$ & 0.58 & 0.45 & 1.93 & 0.90 \\
$\boldsymbol{F e}$ & 43.91 & 24.32 & 0.72 & 0.24 \\
\hline
\end{tabular}

\section{Discussion}

Concerning about the refining mechanism of carbon inoculation of $\mathrm{Mg}-\mathrm{Al}$ alloys, two kinds of $\mathrm{Al}-\mathrm{C}-$ rich compounds $\mathrm{Al}_{4} \mathrm{C}_{3}$ and $\mathrm{Al}_{2} \mathrm{MgC}_{2}$ were considered to be the potent nuclei for $\mathrm{Mg}$ grains due to the low disregistry with $\alpha$-Mg phase. ${ }^{22)}$ It is worth noting that $\mathrm{Al}-\mathrm{C}-\mathrm{O}$ particles were invariably observed in the carbon-inoculated $\mathrm{Mg}-\mathrm{Al}$ based alloys, ${ }^{42)}$ as the particle A shown in Fig. 7. These Al-C-O particles were supposed to be the hydrolyzate of $\mathrm{Al}_{4} \mathrm{C}_{3}$ or $\mathrm{Al}_{2} \mathrm{MgC}_{2}$ particles via the chemical reaction during sample polishing and etching: $\mathrm{Al}_{4} \mathrm{C}_{3}(\mathrm{~s})+12 \mathrm{H}_{2} \mathrm{O}(\mathrm{l}) \rightarrow 4 \mathrm{Al}(\mathrm{OH})_{3}$ (s) $+\mathrm{CH}_{4}(\mathrm{~g}) \uparrow$ and $2 \mathrm{Al}_{2} \mathrm{MgC}_{2}+8 \mathrm{H}_{2} \mathrm{O}=2 \mathrm{MgAl}_{2} \mathrm{O}_{4}+$ $4 \mathrm{CH}_{4} \uparrow{ }^{43)}$ The Al-C-O phase was named as Al-C-rich compounds $\left(\mathrm{Al}_{4} \mathrm{C}_{3}\right.$ or $\left.\mathrm{Al}_{2} \mathrm{MgC}_{2}\right)$ to avoid confusion in the following statement. In addition, effective grain refinement could be obtained for due to $\mathrm{Ca}$ addition. The refining mechanism was attributed to an intensive constitutional undercooling region in front of the advancing solid/liquid interface due to strong segregation ability of $\mathrm{Ca}$ during solidification. ${ }^{4,44,45)}$ In our previous studies, ${ }^{25,27)}$ it has been validated that a higher grain refining efficiency was able to be acquired by carbon combining with $\mathrm{Ca}$ inoculation. Known from Figs. 5 and 7, there exist two types of particles (Al-C$\mathrm{O}$ and $\mathrm{Al}-\mathrm{Ca}$-rich particles) in the refined $\mathrm{Mg}-3 \% \mathrm{Al}$ alloy by carbon combining with $\mathrm{Ca}$ inoculation. Addition of $\mathrm{Mg}-$ $10 \mathrm{Ca}$ master alloy into the $\mathrm{Mg}-3 \% \mathrm{Al}$ melt would cause the reaction of $\mathrm{Al}$ and $\mathrm{Ca}$. Significant grain refinement was 

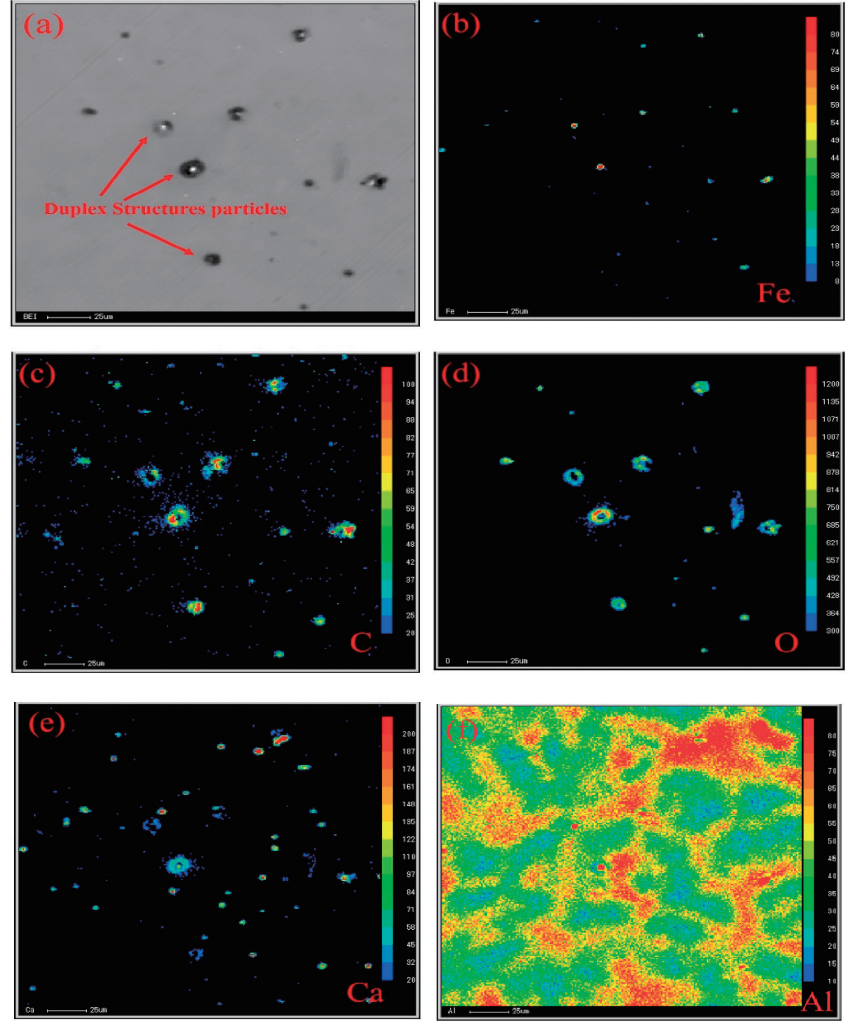

Fig. 10 EPMA-WDS map analysis of $\mathrm{Mg}-3 \% \mathrm{Al}-0.05 \% \mathrm{Fe}$ refined by carbon combining with $\mathrm{Ca}$ inoculation with the holding time of $80 \mathrm{~min}$ (a) The region of EPMA-WDS map analysis; (b)-(f) The distribution of $\mathrm{Fe}, \mathrm{C}, \mathrm{O}, \mathrm{Ca}$ and $\mathrm{Al}$ element, respectively.

obtained and no inoculant fading occurred even though the holding time was prolonged to $80 \mathrm{~min}$. The results indicate that the nucleating particles are stable in the $\mathrm{Mg}-3 \% \mathrm{Al}$ melt refined by carbon combing with $\mathrm{Ca}$ inoculation.

As an inevitable impurity element, the debate about the influence of $\mathrm{Fe}$ on grain refinement of $\mathrm{Mg}-\mathrm{Al}$ based alloys has lasted for decades. Early works suggested that Fe had superior grain refining ability on $\mathrm{Mg}$ alloys. ${ }^{9,28,46)}$ Cao et al. reported that Elfinal process (anhydrous $\mathrm{FeCl}_{3}$ addition) could refine the high purity $\mathrm{Mg}-3 \% \mathrm{Al}$ and $\mathrm{Mg}-9 \% \mathrm{Al}$ alloys. ${ }^{9)}$ In other studies, it was found that $\mathrm{Fe}$ disturb the refining effect for some grain refinement processes, such as pure $\mathrm{Mg}$ refined by $\mathrm{Zr}^{47}$ ) and $\mathrm{Mg}-\mathrm{Al}$ alloy inoculated by carbon. ${ }^{25)} \mathrm{Fe}$ had ever been regarded as a poisoning element by transforming from $\mathrm{Al}-\mathrm{C}$-rich nuclei into $\mathrm{Al}-\mathrm{C}-\mathrm{Fe}-$-rich compound. ${ }^{24,48)}$ This ternary compound is not easy to be detected due to its low number density in the alloys and its accurate structure has not been revealed in details. Many researchers had proved that $\mathrm{Al}-\mathrm{C}-\mathrm{Fe}$ phase could not be heterogeneous nucleus of $\alpha-\mathrm{Mg}$ in $\mathrm{Mg}-\mathrm{Al}$ based alloys. ${ }^{7,49-51)}$ However, Pan et al. considered that the $\mathrm{Al}-\mathrm{C}-\mathrm{O}-\mathrm{Fe}(\mathrm{Mn})$-rich particles could act as nucleating site of $\alpha-\mathrm{Mg}$ grain. ${ }^{28)}$ In the present study, the addition of different level of Fe could not refine high purity $\mathrm{Mg}-3 \% \mathrm{Al}$ alloy, as displayed in Fig. 1. Moreover, $\mathrm{Fe}$ had little influence on grain refinement of $\mathrm{Mg}-3 \% \mathrm{Al}$ alloy refined by carbon combining with $\mathrm{Ca}$ inoculation, as shown in Figs. 3 and 4.

In the present study, $\mathrm{Ca}$ and $\mathrm{Fe}$ were added in $\mathrm{Mg}-3 \% \mathrm{Al}$ melt by $\mathrm{Mg}-10 \% \mathrm{Ca}$ and $\mathrm{Al}-15 \% \mathrm{Fe}$ master alloys. $\mathrm{Mg}-$ $10 \% \mathrm{Ca}$ alloys would be decomposed and $\mathrm{Ca}$ was dissolved
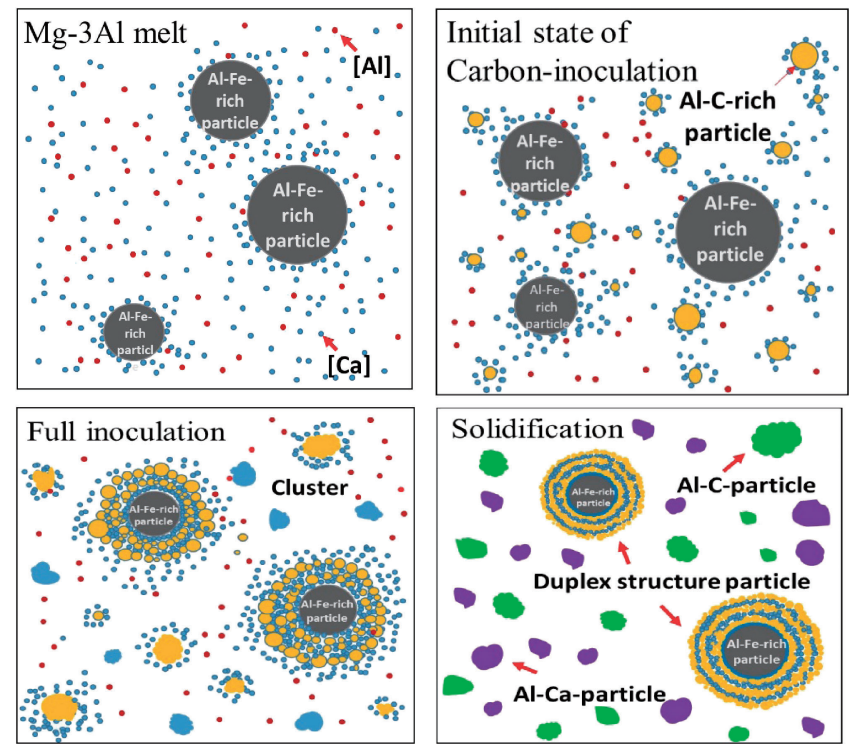

Fig. 11 Schematic diagram of the formation processes of duplex-phase structure particle.

into the melt as a solute since the solubility of $\mathrm{Ca}$ in $\mathrm{Mg}$ melt is about $0.8 \%$ at $760^{\circ} \mathrm{C} .^{52)} \mathrm{Al}-\mathrm{Ca}$-rich particles were the resultant of $\mathrm{Al}$ and $\mathrm{Ca}$ reaction in the $\mathrm{Mg}-3 \% \mathrm{Al}$ melt during the cooling process. In our previous research, grain refining effect could not be obtained by $\mathrm{Fe}$ and $\mathrm{Ca}$ addition. ${ }^{27)}$ These Al-Ca-rich particles were not possible to be the potent nucleant particles for $\alpha-\mathrm{Mg}$ grains. As for the $\mathrm{Al}-15 \% \mathrm{Fe}$ alloy, there existed $\mathrm{AlFe}_{3}$ and AlFe phases. ${ }^{25)}$ Some Al-Ferich particles would remain in the melt due to the high melting point and low solubility of $\mathrm{Fe}$ in $\mathrm{Mg}$ melt. The $\mathrm{Ca}$ solute would segregate in the surface of Al-Fe-rich particles since it is a surface active element.

After being carbon-inoculated, the Al-C-rich particles had already formed in the $\mathrm{Mg}-3 \% \mathrm{Al}$ melt. These $\mathrm{Al}-\mathrm{C}$-rich particles are very small with the size of less than $100 \mathrm{~nm}$ during the initial stage of carbon-inoculation. ${ }^{11)}$ These tiny Al-C-particles could spontaneously gather and grow to large particles. The inoculation and solidification processes for the $\mathrm{Mg}-3 \% \mathrm{Al}$ melt containing Fe refined by carbon combining with $\mathrm{Ca}$ inoculation are possibly constituted as the following paths. Firstly, the Al-Fe-rich particles would pre-exist in the $\mathrm{Mg}-3 \% \mathrm{Al}$ melt due to the addition of $\mathrm{Al}-15 \% \mathrm{Fe}$ master alloy. The solute of $\mathrm{Ca}$ were segregated around the Al-Ferich particles. Secondly, the Al-C-rich particles were formed by a reaction between $\mathrm{Al}$ and $\mathrm{C}$ after the carbon-containing pellets were plunged into the melt. Some tiny Al-C-rich particles were adsorbed on the surfaces of Al-Fe-rich particles due to its high surface energy. Finally, the duplex phase structure particles were formed by Al-C-rich particles coated on the Al-Fe-rich particles. In addition, a large number of $\mathrm{Ca}$ atoms were precipitated from the melt during the solidification. These enrichment of $\mathrm{Ca}$ atoms would be further reaction with $\mathrm{Al}$ and these reaction would generate a stable Al-Ca-rich particle. The formation processes of duplex-phase structure particle are simply depicted in Fig. 11. In the present study, many typically duplex phase structure particles were discovered in the $\mathrm{Mg}$ grains. However, no obvious duplex phase structure particles were 
found in the sample of $\mathrm{Mg}-3 \% \mathrm{Al}-0.1 \% \mathrm{Fe}$ melt was fully inoculated by $0.2 \% \mathrm{C}$ without $\mathrm{Ca}$ addition. ${ }^{51)}$ Therefore, the formation of duplex-phase particles was attributed to $\mathrm{Ca}$ addition. $\mathrm{Ca}, \mathrm{C}$ and $\mathrm{O}$ elements always overlap in the duplexphase particles, as shown in Figs. 10(c) to (e). The Ca content in the shell area is about five to ten times as high as that in $\mathrm{Mg}$ matrix, as the result shown in Figs. 8 and 9. With the prolonging holding time, more and more solute of $\mathrm{Ca}$ was segregated to the duplex phase structure particles. As a consequence, the number of Al-Ca-rich particles were decreased as shown in the Fig. 6. The grain size is also determined by the number and distribution of effective nucleated particles in the constitutional undercooling region. In practice, it is found that the nucleated particles which play the role of heterogeneous nucleation are often less than $1 \%$ of the total nucleation particles. ${ }^{42)}$ According to the free growth model:

$$
\Delta T_{n}=\frac{4 \sigma_{S L}}{\Delta s_{v} d_{p}}
$$

where $\Delta T_{n}$ is nucleation undercooling, $\sigma_{S L}$ is the solid-liquid interface energy, $\Delta s_{v}$ is the entropy of fusion per unit volume and $d_{p}$ is the diameter of the nucleation particle. Many small size nucleation particles can not be used as an effective heterogeneous nucleation particle due to the large nucleation undercooling $\left(\Delta T_{n}\right)$ required. $\mathrm{Ca}$ is tendency to segregate on the interfaces between different phases and attributes to the formation of duplex-phase particles. These duplex-phase structure will increase the size of nucleation particles $\left(d_{p}\right)$. Therefore, more nucleation particles meet the required nucleation undercooling due to the decrease of the nucleation undercooling $\left(\Delta T_{n}\right)$. Consequently, the number of nucleated particles increases with the addition of $\mathrm{Ca}$. The relationship between constitutional undercooling $\Delta T_{c s}$ and solid phase mass fraction $f_{S}$ can be obtained: ${ }^{53)}$

$$
\Delta T_{C S}=m_{l} c_{0}\left(1-\frac{1}{\left(1-f_{s}\right)^{P}}\right)
$$

Where $m_{l}$ is the slope of the liquids, $c_{0}$ is the alloy composition, $P=1-k, k$ is the equilibrium distribution coefficient. At the beginning of solidification, the undercooling of initial nucleation is provided or triggered by the constitutional undercooling produced by the solute segregation. The nucleation events occur on the criterion matches $\Delta T_{c s}=\Delta T_{n}$. The increase rate of constitutional undercooling $m$ can be calculated by eq. (2):

$$
m=\frac{d \Delta T_{C s}}{d \Delta f_{s}}
$$

At the beginning of solidification $f_{s} \rightarrow 0$, the increase rate of constitutional undercooling is about 0.49 and 0.13 with and without $\mathrm{Ca}$ addition, calculated by eq. (3). This shows that $\mathrm{Ca}$ addition can quickly establish the constitutional undercooling zone at the front of the solid-liquid interface at the beginning of solidification. $\mathrm{Ca}$ is tendency to segregate on the interfaces of the solid-liquid, which can increase the rate of constitutional undercooling and promote the occurrence of heterogeneous nucleation.

It is well known that the chemical and structural stabilities of inoculant particles are the key factors to determine the grain refinement. There existed many duplex-phase particles with Al-C-rich phase coated on Al-Fe phase. Actually, the real potent nucleation particles were the shell of duplex-phase particles which was constituted by $\mathrm{Al}-\mathrm{C}$-rich phase. In our previous research, inoculation fading phenomenon was occurred in the $\mathrm{Mg}-3 \% \mathrm{Al}$ alloy containing $0.1 \%$ Fe refined by carbon inoculation due to the poisoning effect of $\mathrm{Fe}$ by transforming the Al-C-rich phase to Al-C-Fe-rich phase. ${ }^{38)}$ In this study, grain sizes of $\mathrm{Mg}-3 \% \mathrm{Al}$ alloy containing different trace $\mathrm{Fe}$ contents kept stable even though the holding time was prolonged to $80 \mathrm{~min}$. These results may attribute to the stable of the duplex-phase structure particles as shown in Fig. 6. Ca solute segregates on the surface of some phases or the interfaces between different phases and keep the duplex-phase structure particles stable. The enrichment of $\mathrm{Ca}$ atoms around the interfaces of $\mathrm{Al}-\mathrm{Fe}$-rich phase and Al-C-rich phase could inhibit the reaction of different phases. Consequently, Fe could not accelerate inoculant fading of carbon-inoculation due to the high stability of the duplex phase structure particles.

\section{Conclusions}

(1) Significant grain refining efficiency is acquired for the $\mathrm{Mg}-3 \% \mathrm{Al}$ alloy containing different trace $\mathrm{Fe}$ contents refined by carbon combining with $\mathrm{Ca}$ inoculation. The grain size keep stable with prolonging the holding time and no inoculant fading occurred.

(2) The duplex-phase particles of Al-C-rich phase coated on $\mathrm{Al}-\mathrm{Fe}$ phase is easily observed in the $\mathrm{Mg}-3 \% \mathrm{Al}$ alloy containing $\mathrm{Fe}$ refined by carbon combining with $\mathrm{Ca}$ inoculation. These particles should be the potent nuclei for $\mathrm{Mg}$ grains.

(3) $\mathrm{Ca}$ is tendency to segregate on the interfaces between different phases and attributes to the formation of duplex-phase particles. The Ca content in the Al-C-rich shell is distinctly higher than that in the $\mathrm{Mg}$ matrix.

(4) The enrichment of $\mathrm{Ca}$ atoms through adsorption on the surfaces can effectively inhibit the reaction among different phases and keep the duplex-phase structure particles stable. Consequently, Fe could not accelerate inoculant fading of carbon-inoculation due to the high stability of the duplex phase structure particles.

\section{Acknowledgments}

This work was supported by the National Natural Science Foundation of China (51574127) and Natural Science Foundation of Guangdong Province (2014A030313221).

\section{REFERENCES}

1) F.S. Pan, M.B. Yang and X.H. Chen: J. Mater. Sci. Technol. 32 (2016) 1211-1221.

2) X.J. Wang, D.K. Xu, R.Z. Wu, X.B. Chen, Q.M. Peng, L. Jin, Y.C. Xin, Z.Q. Zhang, Y. Liu, X.H. Chen, G. Chen, K.K. Deng and H.Y. Wang: J. Mater. Sci. Technol. 34 (2018) 245-247.

3) H. Yu, Y. Xin, M. Wang and Q. Liu: J. Mater. Sci. Technol. 34 (2018) $248-256$.

4) Z.T. Jiang, B. Jiang, J.Y. Zhang, J.H. Dai, Q.S. Yang, Q. Yang and F.S. Pan: Trans. Nonferrous Met. Soc. China 26 (2016) 1284-1293. 
5) M. Sun, X. Hu, L. Peng, P. Fu and Y. Peng: Mater. Sci. Eng. A 620 (2015) 89-96.

6) G. Han and X.F. Liu: Acta Mater. 114 (2016) 54-66.

7) P. Cao, M. Qian and D.H. StJohn: Scr. Mater. 56 (2007) 633-636.

8) D. Qiu, M.X. Zhang, J.A. Taylor, H.M. Fu and P.M. Kelly: Acta Mater. 55 (2007) 1863-1871.

9) P. Cao, M. Qian and D.H. StJohn: Scr. Mater. 51 (2004) 125-129.

10) A.M. Zhang, H. Hao and X.G. Zhang: Trans. Nonferrous Met. Soc. China 23 (2013) 3167-3172.

11) J. Du, M.H. Wang, M. Zhou and W.F. Li: J. Alloys Compd. 592 (2014) 313-318

12) T. Wang, T. Gao, J. Nie, P. Li and X. Liu: Mater. Charact. 83 (2013) $13-20$

13) J. Du, Y. Shi, M. Zhou and W. Li: J. Mater. Sci. Technol. 32 (2016) 1297-1302.

14) U. Joshi and N.H. Babu: J. Alloys Compd. 695 (2017) 971-975.

15) J. Gu, Y.D. Huang, M.X. Zhang, K.U. Kainer and N. Hort: Magnesium Technology 2017, (Springer International Publishing Ag, Cham, 2017) pp. 191-198.

16) Z.H. Wang, X.L. Zhang, S.B. Li, K. Liu and W.B. Du: Mater. Sci. Forum 788 (2014) 98-102.

17) M. Suresh, A. Srinivasan, U.T.S. Pillai and B.C. Pai: Procedia Eng. 55 (2013) 93-97.

18) M. Yang, F. Pan, R. Cheng and A. Tang: Mater. Sci. Eng. A 491 (2008) $440-445$.

19) K. Li, F. Wang, Q. Wang and N.G. Zhou: Journal of Shanghai Jiaotong University (Science) 17 (2012) 301-305.

20) M. Qian and P. Cao: Scr. Mater. 52 (2005) 415-419.

21) Y. Ali, D. Qiu, B. Jiang, F. Pan and M.X. Zhang: J. Alloys Compd. 619 (2015) 639-651.

22) M.X. Zhang, P.M. Kelly, M. Qian and J.A. Taylor: Acta Mater. 53 (2005) 3261-3270.

23) G. Han and X. Liu: J. Alloys Compd. 487 (2009) 194-197.

24) Y. Tamura, T. Haitani, E. Yano, T. Motegi, N. Kono and E. Sato: Mater. Trans. 43 (2002) 2784-2788.

25) J. Du, M. Wang and W. Li: J. Alloys Compd. 502 (2010) 74-79.

26) F. Pan, X. Chen, T. Yan, T. Liu, J. Mao, W. Luo, Q. Wang, J. Peng, A. Tang and B. Jiang: Journal of Magnesium and Alloys 4 (2016) 8-14.

27) J. Du, H.L. Wang, M.C. Zhou and W.F. Li: Trans. Nonferrous Met. Soc. China 23 (2013) 307-314.

28) Y. Pan: J. Mater. Sci. Technol. 21 (2005) 2005.

29) S. Kim, S.L. Cockcroft and A.M. Omran: J. Alloys Compd. 476 (2009)
$728-732$.

30) P. Chaengkham and P. Srichandr: J. Mater. Process. Technol. 211 (2011) 1372-1378

31) Y. Birol: J. Alloys Compd. 513 (2012) 150-153.

32) T.M. Wang, H.W. Fu, Z.N. Chen, J. Xu, J. Zhu, F. Cao and T.J. Li: J. Alloys Compd. 511 (2012) 45-49.

33) A.W. Yu, C.G. Yang, F.C. Liu, Q. Zheng, Y.F. Liao and H. Chen: Rare Met. Mater. Eng. 44 (2015) 1964-1969.

34) T. Kanno, Y. Iwami and I. Kang: Int. J. Metalcast. 11 (2017) 94-100.

35) M. Chakraborty, G.S.V. Kumar and B.S. Murty: Trans. Indian Inst. Met. 58 (2005) 661-670.

36) T.J. Chen, X.D. Jiang, Y. Ma, R.Q. Wang and Y. Hao: Mater. Res. 14 (2011) 124-133.

37) T.J. Chen, Y. Ma, W.B. Lv, Y.D. Li and Y. Hao: J. Mater. Sci. 45 (2010) 6732-6738.

38) J. Du and M.H. Wang: J. Mater. Eng. 44 (2016) 54-58.

39) M. Yamasaki, K. Hashimoto, K. Hagihara and Y. Kawamura: Acta Mater. 59 (2011) 3646-3658

40) T. Ito, M. Noda, H. Mori, Y. Gonda and Y. Fukuda: Mater. Trans. 55 (2014) 1184-1189

41) A. Standard, Standard Test Methods for Determining Average Grain Size, 3 (ASTM Pub., Pennsylvania, USA, 1993) pp. 297-322.

42) Y.Z. Zhao, X.T. Liu and H. Hao: Acta Metall. Sin. (Engl. Lett.) 30 (2017) 505-512.

43) Y. Huang, K.U. Kainer and N. Hort: Scr. Mater. 64 (2011) 793-796.

44) Y. Ali, D. Qiu, B. Jiang, F. Pan and M.X. Zhang: Scr. Mater. 114 (2016) 103-107.

45) S.S. Li, B. Tang and D.B. Zeng: J. Alloys Compd. 437 (2007) 317-321.

46) Emley, Principles of Magnesium Technology, (Pergamon Press, 1966).

47) P. Cao, M. Qian, D.H. StJohn and M.T. Frost: Mater. Sci. Technol. 20 (2004) 585-592.

48) Y. Tamura, T. Motegi, N. Kono and E. Sato: Mater. Sci. Forum 350351 (2000) 199-204.

49) P. Cao, M. Qian and D.H. StJohn: Scr. Mater. 53 (2005) 841-844.

50) M.Q.a.D.S. Peng Cao: Magnesium Technology, (The Minerals, Metals and Materials Society, Warrendale, PA, 2005) pp. 297-302.

51) J. Du, J. Yang, M. Kuwabara, W. Li and J. Peng: Mater. Trans. 48 (2007) 2903-2908

52) In Binary Systems. Part 1 Elements and Binary Systems from Ag-Al to $A u-T l$, (Springer Berlin Heidelberg, Berlin, Heidelberg, 2002) pp. $122-$ 124.

53) M.A. Easton and D.H. StJohn: Acta Mater. 49 (2001) 1867-1878. 